Canadian Journal of Fisheries and Aquatic Sciences Journal canadien des sciences halieutiques et aquatiques

\title{
Sampling the stream landscape: improving the applicability of an ecoregion-level capture probability model for stream fishes
}

\begin{tabular}{|c|c|}
\hline Journal: & Canadian Journal of Fisheries and Aquatic Sciences \\
\hline Manuscript ID & cjfas-2016-0422.R3 \\
\hline Manuscript Type: & Article \\
\hline Date Submitted by the Author: & $18-N o v-2017$ \\
\hline Complete List of Authors: & $\begin{array}{l}\text { Mollenhauer, Robert; Oklahoma Cooperative Fish and Wildlife Research } \\
\text { Unit, Oklahoma State University } \\
\text { Mouser, Joshua; Oklahoma Cooperative Fish and Wildlife Research Unit, } \\
\text { Oklahoma State University } \\
\text { Brewer, Shannon; U.S. Geological Survey, Oklahoma Cooperative Fish and } \\
\text { Wildlife Research Unit }\end{array}$ \\
\hline \multirow[t]{2}{*}{$\begin{array}{r}\text { Is the invited manuscript for } \\
\text { consideration in a Special } \\
\text { Issue? : }\end{array}$} & N/A \\
\hline & $\begin{array}{l}\text { FRESHWATER < Environment/Habitat, STREAMS < Environment/Habitat, } \\
\text { ABUNDANCE < General, FISHERY MANAGEMENT < General, SAMPLING < } \\
\text { General }\end{array}$ \\
\hline
\end{tabular}

\section{SCHOLARONE \\ Manuscripts}


1 Sampling the stream landscape: improving the applicability of an ecoregion-level capture

2 probability model for stream fishes

3

$4 \quad$ Robert Mollenhauer ${ }^{1}$, Joshua Mouser ${ }^{1}$, and Shannon K. Brewer ${ }^{2}$

5

$6{ }^{1}$ Oklahoma Cooperative Fish and Wildlife Research Unit, Oklahoma State University,

7 Stillwater, OK, 74078 USA.

8

$9 \quad{ }^{2}$ U.S. Geological Survey, Oklahoma Cooperative Fish and Wildlife Research Unit, Oklahoma

10 State University, Stillwater, OK, 74078 USA E-mail: shannon.brewer@okstate.edu, Telephone:

$11 \quad$ (405) 744-9841; Fax: (405) 744-5006.

12

13

14

15

16

17

18

19

20

21

22 


\section{Abstract}

24 Temporal and spatial variability in streams results in heterogeneous gear capture probability (i.e.,

25 the proportion of available individuals identified) that confounds interpretation of data used to

26 monitor fish abundance. We modeled tow-barge electrofishing capture probability at multiple

27 spatial scales for nine Ozark Highland stream fishes. In addition to fish size, we identified seven

28 reach-scale environmental characteristics associated with variable capture probability: stream

29 discharge, water depth, conductivity, water clarity, emergent vegetation, wetted width-depth

30 ratio, and proportion of riffle habitat. The magnitude of the relationship between capture

31 probability and both discharge and depth varied among stream fishes. We also identified

32 lithological characteristics among stream segments as a coarse-scale source of variable capture

33 probability. The resulting capture probability model can be used to adjust catch data and derive

34 reach-scale absolute abundance estimates across a wide range of sampling conditions with

35 similar effort as used in more traditional fisheries surveys (i.e., catch-per-unit effort). Adjusting

36 catch data based on variable capture probability improves the comparability of datasets, thus

37 promoting both well-informed conservation and management decisions and advances in stream-

38 fish ecology. 


\section{Introduction}

Perceived fish distributions across the dynamic stream landscape are largely influenced by the timing and nature of sampling (Jackson et al. 2001; Poff and Zimmerman 2010; Gwinn et al. 2016). Variation in capture probability (i.e., the proportion of available individuals captured) among sampling methods, environmental conditions, and species hinders our ability to effectively detect changes in stream-fish abundance and assemblage structure. The importance of addressing variable capture probability as a basis for sound management and conservation has long been recognized by stream-fish researchers (e.g., Cleary and Greenbank 1954; Larimore 1961). Despite improved analytical approaches to account for variable capture probability (e.g., Williams et al. 2002; MacKenzie et al. 2005; Royle et al. 2013), catch-per-unit-effort (CPUE) remains the most common metric used to evaluate and monitor stream-fish populations (Gwinn et al. 2016). Major limitations of CPUE include calculating only an indirect measure of abundance, relying on a typically untested and often unrealistic assumption of proportional capture probability, and providing no insight about heterogeneity in capture probability among species (see also Gwinn et al. 2016 for a detailed discussion of the inherent limitations of CPUE for stream-fish sampling).

Standardizing sampling conditions (e.g., sampling only at baseflows) to support the use of CPUE may minimize variation in site-specific short-term capture probability. However, maintaining constant capture probability for broad-scale or long-term stream-fish monitoring is challenging because environmental conditions in streams vary extensively across space and time with complex relationships among variables (e.g., interactions at different levels; Jackson et al. 2001; Price and Peterson 2010; Gwinn et al. 2016). Furthermore, identifying relationships between stream fishes and the environment (e.g., flow-ecology relationships), often fundamental 
64 research and management goals, are not possible when limiting sampling to a narrow range of

65 environmental conditions

Sampling gear calibration (Peterson and Rabeni 2001; Peterson and Paukert 2009) is one

67 approach to address the challenges of variable stream-fish capture probability. Gear calibration requires a series of repeat sampling events across a wide range of environmental conditions using

69 either mark-recapture or comparisons with a previously calibrated gear. Data collected during gear calibration can be used to model heterogeneity in capture probability across sampling

71 conditions and among stream fishes. The resulting model estimates capture probability from a

72 single sampling event (i.e., repeat sampling is no longer required) based on site-specific

73 conditions using linear combinations of model coefficients (see Peterson and Paukert 2009).

74 Reduced sampling effort over time is a major long-term benefit of approaches, such as gear

75 calibration, that model capture probability across sites a function of predictor variables (see also

76 Huggins 1991; Pollock 2002; Royle and Dorazio 2006). A reduction in sampling effort over time

77 is not possible with "traditional" methods that account for variable capture probability, but model

78 each site individually without predictor variables (e.g., Zippin 1958; Manly and Seber 1973;

79 Carle and Strub 1978). Analogous to mark-recapture and removal population estimators, the resulting capture probability estimates from the model resulting from gear calibration can be

81 used to adjust raw catch data to an absolute abundance (Huggins 1991; Thompson and Seber

82 1994; Peterson and Paukert 2009). Thus, effective gear calibration can provide temporally- and

83 spatially-comparable abundance estimates with equivalent sampling effort as CPUE, where

84 standardization of sampling conditions is not required. However, an inherent challenge of

85 effective stream-fish sampling gear calibration is capturing the complexity of capture probability 
across environmental conditions while providing an end product that remains practical for implementation into long-term monitoring or research.

Our objective was to develop a practical, flexible, multilevel model to predict capture probability among stream fishes across a wide range of sampling conditions in wadeable warmwater streams using tow-barge electrofishing. We incorporated both fish and multiple instream characteristics into the model. Additionally, we used existing geospatial data to generalize coarse-scale lithological characteristics associated with variable electrofishing capture probability, which was novel to our approach. Previous research addressing stream-fish capture probability has been biased toward salmonids and our study represents a rare effort to model multispecies electrofishing capture probability in wadeable warmwater streams of the southern United States (see also Price and Peterson 2010). We detail an effective, yet straightforward, gear calibration approach that can easily be implemented by stream-fish scientists in other systems or with other sampling methods.

\section{Methods}

Study sites. - We sampled stream fishes in 34 stream reaches (each 0.6-1.0 km in length) of the Ozark Highlands ecoregion in northeast Oklahoma and southwest Missouri during summer 2014-2015 (Fig. 1). The Ozark Highlands ecoregion is characterized by oak-hickory forests, with valleys primarily converted to pasture (Woods et. al 2005). The dominant underlying lithology of the Ozark Highlands is cherty limestone; however, there is considerable variation, particularly near the ecotones. Many Ozark Highland streams are classified as groundwater dominated with clear water (but with substantial variation in water clarity; Nigh and Schroeder 2002). All stream reaches were wadeable (i.e., most habitat was $<1 \mathrm{~m}$ deep; Rabeni et al. 2009) and comprised 
109 three to five riffle-run-pool sequences to characterize stream habitat. We chose stream reaches

110 haphazardly to represent the study area, with final site selection largely driven by access and

111 landowner permission. Our site selection provided considerable environmental variability in

112 sampling conditions (a key aspect of effective gear calibration; Peterson and Paukert 2009) and

113 included stream reaches near the southern ecotone (Table 1; Fig.1). We sampled stream reaches

114 that were either $>2$ stream $\mathrm{km}$ apart or we resampled the same site under different environmental

115 conditions $>60 \mathrm{~d}$ apart (typically both) to ensure independent surveys (i.e., capture probability at

116 a stream reach was not influenced by sampling at another reach). Any spatial dependence among

117 stream reaches associated with capture probability not explained by predictor variables was

118 accounted for with a random stream reach effect (see capture probability model methods below).

119 We focused on estimating the capture probability of nine common centrarchid species, including 120 popular sportfishes (Table 2). Centrarchids recover quickly from electrofishing with minimal

121 mortality (Bardygula-Nonn et al. 1995; Dolan et al. 2002; Dolan and Miranda 2004).

122 Fish sampling. - We installed two sets of block-off nets at both the upstream and downstream

123 end of each stream reach to close the system. Block-off nets were preferentially placed at

124 shallow riffles to further inhibit fish movement (Peterson et al. 2004; Price and Peterson 2010).

125 Either a low-water bridge at low flow $(n=5)$ or a dry riffle located at one end of the reach

126 provided adequate fish barriers in some instances and no block-off nets were installed.

128 Management, Polo, Missouri) and angling to establish marked populations of centrarchids.

129 Sampling methods were not standardized on marking day because our objective was to capture

130 and mark as many fish as possible. We used angling primarily to increase the number of marked

131 smallmouth bass (Micropterus dolomieu) because electrofishing capture probability is often low 
132 for this species (Lyons and Kanehl 1993; Dauwalter and Fisher 2007; Mollenhauer and Brewer 133 2017), although other captured centrarchids were also included in the marked population.

134 Approximately 300 of the over 17,000 fish were captured via angling. Captured fish were 135 identified to species, measured (1.0-mm TL), and marked with a caudal fin clip. All crew were 136 trained in both fish identification and standardized American Fisheries Society measurement 137 techniques (Neumann et al. 2013). The minimum size of fish included in the marked population 138 was 50-mm TL for Lepomis and rock bass (Ambloplites rupestris) and 80-mm TL for 139 Micropterus. Our size restrictions excluded most age-0 fishes not recruited to electrofishing 140 (McClendon and Rabeni 1986) and was also based on observed mortalities for very small 141 centrarchids (Dolan and Miranda 2004; personal observations). Marked fish were released 142 throughout the stream reach and allowed to recover and redistribute for $\approx 48 \mathrm{~h}$. The time between 143 electrofishing events was double the commonly accepted guideline for system recovery 144 (Peterson and Cederholm 1984; Peterson et. al 2004). We also did not release marked fish until 145 the sampling crew had proceeded a minimum of one riffle-run-pool sequence away to minimize 146 the probability of being recaptured. Fish injured during sampling or that exhibited signs of 147 excessive stress were released outside the blocked-off area. We used multiple methods to assess delayed fish mortality and determined it was negligible. The blocked-off area was routinely inspected from the surface for dead marked centrarchids, which were removed from the study ( $<0.05 \%$ of the marked fish population). As 151 an additional assessment of fish mortality, a snorkel pass was performed at stream reaches with 152 reasonable water clarity $(n=22)$ prior to the recapture event to identify dead centrarchids (none 153 were found). 

electrofishing passes per riffle-run-pool sequence. The electrofishing crew comprised three people: one tow-barge operator armed with a hand net and two persons equipped with dip nets,

157 each operating one of the anodes. We used pulsed direct current, $60 \mathrm{~Hz}$, and a $25 \%$ duty cycle 158 for electrofishing. Voltage was adjusted to a target power (W) to reduce variation in the electrical 159 field across levels of ambient water conductivity while minimizing electrofishing-induced 160 injuries as described by Miranda (2009). We thoroughly sampled areas $\geq 0.2-\mathrm{m}$ deep in an 161 upstream direction with a zigzag pattern (i.e., not parallel to the stream channel). Logistic 162 constraints of the tow-barge made very shallow habitats difficult to sample effectively, although 163 use of these habitats is uncommon by centrarchids (Probst et al. 1984; Schlosser 1987; Brewer 164 2013). Recaptured centrarchids were identified to species and measured (TL). We also identified 165 and measured unmarked fish to provide estimates of relative densities among reaches.

166 Environmental measurements. - We measured reach-scale instream characteristics hypothesized 167 to influence electrofishing capture probability of stream fishes (Table 2). A conductivity pen 168 (Myron L Company, Carlsbad, California; Model PT1) was used to measure water temperature $169\left(0.1^{\circ} \mathrm{C}\right)$ and ambient water conductivity $(1.0 \mu \mathrm{S} / \mathrm{cm})$ at the downstream end of each stream 170 reach. Wetted channel width $(1.0 \mathrm{~m})$ and thalweg depth $(0.1 \mathrm{~m})$ were measured at $50-\mathrm{m}$ 171 transects. Stream discharge $\left(0.01 \mathrm{~m}^{3} \cdot \mathrm{s}^{-1}\right)$ was measured in a homogenous area of a run using the 172 velocity-area method (Gordon et al. 2004). Water clarity (0.5 m) was measured as the horizontal 173 distance an underwater observer could see a fish silhouette. We used both the same observer and 174 fish silhouette at all stream reaches to maintain consistency (Dunham et al. 2009). The fish 175 silhouette was designed to mimic the color, markings, and typical size $(\approx 200 \mathrm{~mm})$ of smallmouth 176 bass in our study streams. GPS coordinates were recorded at both the upstream and downstream 
177 end of each stream reach to estimate length $(1.0 \mathrm{~m})$. We also measured riffle lengths $(1.0 \mathrm{~m})$ to

178 calculate the proportion of riffle habitat relative to the length of each stream reach. Both instream

179 large wood (i.e., instream trees, logs, and rootwads) and emergent vegetation were estimated as

180 the length $(1.0 \mathrm{~m})$ and width $(1.0 \mathrm{~m})$ of each patch to calculate proportional coverage.

We used geospatial data to classify stream segments (defined as a length of stream

182 between third-order tributaries) by lithology. We based our classifications on both rock fragment

183 type (Miller and White 1998; Pennsylvania State University 2008) and geology type (USGS

184 2005): cherty limestone, cherty alluvium, stony alluvium, and shale (hereafter referred to

185 "geosoil" categories). The geosoil categories generalized lithological characteristics among

186 stream reaches and provided surrogates for substrate and streambank characteristics (e.g.,

187 streambed complexity and interstitial spaces) that could influence capture probability. We

188 generated a 50-m buffer around each stream segment using ArcMap (version 10.2.1, ESRI, Red

189 Lands, California) and the dominant geosoil type was used to characterize each segment.

190 Capture probability model. - We modeled heterogeneity in electrofishing capture probability

191 among centrarchids across environmental conditions using a generalized linear mixed model

192 (GLMM). GLMMs are a flexible, powerful class of statistical models with a hierarchical (i.e.,

193 multilevel) framework that allow for the inclusion of random effects (Gelman and Hill 2007).

194 Random effects broaden the scope of inference, account for a lack of independence among

195 observations (i.e., pseudoreplication), and accommodate both the inherent multiscale structure of

196 stream systems and unequal sample sizes common in ecological data (Wagner et al. 2006; Jamil

197 et al. 2013). We implemented models using the package lme4 (Bates et al. 2014) in the statistical

198 software R (version 3.3.0, R Core Development Team, 2016). 
Capture probability was modeled as a Bernoulli process with a binomial error

200

201

202

203

204

205

206

207

208

209

210

211

212

213

214

215

216

217

218

219

220

221 distribution, where recapture was a binary response variable for each marked fish (i.e., $1=$

recaptured, $0=$ not recaptured). We assigned recaptures by matching each recaptured fish to a marked fish of the same species \pm 5.0 - $\mathrm{mm}$ TL to incorporate a fish size predictor variable into the model. Individual fish recognition was not required from a modeling perspective (e.g., if two of five smallmouth bass $\approx 200$-mm TL were recaptured, the results of the model would have been identical regardless of which two were assigned as recapture). Accurate species identification and measurements within 5.0-mm TL were essential for reliable results. Given our crew training requirements (see above), we were confident this level of accuracy in our TL measurements was reasonable. Although we accounted for species identity and fish size (both critical for estimating electrofishing capture probability), we made other common mark-recapture assumptions with respect to individual variation (e.g., marked fish behaved similarly to unmarked fish, all fish of a given size and species had equal capture probability, etc.; Williams et al. 2002). We considered multiple reach-level environmental characteristics and the segment-level geosoil categories in the model as predictor variables, where shale was the reference geosoil category. Random intercepts for both stream reach and stream segment were included in the model. We also treated species as a random effect to develop a multispecies model (i.e., model each species simultaneously). In addition to including a random species intercept, we allowed the reach-level predictor variables to vary by species (i.e., random species slopes) to account for heterogeneity in capture probability among species in relation to instream characteristics. The most complex form of our model can be expressed as

$$
\operatorname{logit}\left(p_{i}\right)=\alpha_{j[i]}+\gamma_{k[i]}+\varsigma_{m[k]}+\beta_{1} x_{i}+\beta_{2} \mathrm{CL}_{m}+\beta_{3} \mathrm{CA}_{m}+\beta_{4} \mathrm{SA}_{m}+\sum_{z=5}^{n}\left(\beta_{z} v_{k}-b_{j[k]}\right),
$$
for $i=1,2, \ldots n$ 


$$
\left(\begin{array}{c}
\alpha_{j} \\
b_{j}
\end{array}\right) \sim N\left(\begin{array}{cc}
\sigma_{\alpha}^{2} & \rho \sigma_{\alpha} \sigma_{b} \\
\rho \sigma_{\alpha} \sigma_{b} & \sigma_{b}^{2}
\end{array}\right), \text { for } j=1,2, \ldots . J
$$

222

223

224

225

226

227

228

229

$$
\gamma_{k} \sim N\left(0, \sigma_{\gamma}^{2}\right), \text { for } k=1,2, \ldots . . K
$$

$$
\varsigma_{m} \sim N\left(0, \sigma_{\varsigma}^{2}\right), \text { for } m=1,2, \ldots . M,
$$

where $p$ is estimated capture probability for fish $i, \alpha$ is a random intercept indexing species $j, \gamma$ is a random intercept indexing stream reach $k$ of stream segment $m, \varsigma$ is a random intercept indexing segment $m, x$ is the fish-level continuous variable TL, CL is the cherty-limestone segment-level geosoil category, $\mathrm{CA}$ is the cherty-alluvium segment-level geosoil category, SA is the stony-alluvium segment-level geosoil category, $v$ is a reach-level continuous variable, and $b$ is the random slope for species $j$. All continuous variables were natural-log transformed due to right-skewed distributions and standardized such that each had a mean of zero and a variance of one to improve interpretation of model coefficients and promote model convergence.

We used a selection procedure that both promoted parsimony and resulted in a final model that could be used to predict electrofishing capture probability among centrarchids at the reach scale across a range of sampling conditions. We fitted models using a tiered forward selection process similar to Jamil et al. (2013). The tiered forward selection facilitated the identification of predictor variables related to heterogeneity in capture probability across and among species at different model levels (i.e. fish, stream reach, and stream segment). It was not reasonable to develop a comprehensive competing model set given the number of predictor variables being examined and the interest in species-dependent relationships. Further, use of a backward selection process would have resulted in model convergence issues for the most complex models. Forward selection also allowed correlated predictor variables to be removed as model complexity increased rather than prior to model fitting. Thus, relative model fit can be assessed before removing correlated predictor variables from the analysis. We assessed models 
244 using SigAIC (Broman and Speed 2002; Jamil et al. 2012, 2013). SigAIC is a variant of Akaike 245 information criterion (Burnham and Anderson 2001) that introduces a higher penalty factor $(c)$ 246 for increased model complexity, where we used $\chi_{(0.05)}^{2}=3.84$. At each step in the model-fitting 247 process, a predictor variable or interaction term was retained if it decreased SigAIC by $\geq 1$. Our 248 initial (null) model contained only the random intercepts (stream reach, stream segment, and 249 species). For the first tier, we added the fish-level predictor total length as a main effect to 250 account for variation in capture probability due to fish size before examining species-dependent 251 environmental characteristics. We considered 13 reach-level predictor variables during the 252 second tier, where variables were added only as species-dependent random terms (Table 2). The 253 main effects of reach-level variables were not considered during the second tier because the 254 random model components partly accounted for them and it allowed us to better isolate species255 dependent relationships (Jamil et al. 2013). We considered both individual reach-level predictor 256 variables and two-way interactions for variables with $|r|<0.50$, where $r$ is the Pearson's product257 moment correlation coefficient. At each step of the second tier, we retained the reach-level 258 variable or interaction term that most decreased SigAIC. Remaining variables with $|r| \geq 0.50$ 259 were eliminated as each reach-level variable or interaction term was added to the model. The 260 second tier concluded by adding the main effects for selected reach-level predictor variables. The 261 objective of the third tier was to identify reach-scale predictor variables related to heterogeneity 262 in capture probability across species, where we examined variables that were not selected or 263 eliminated via correlations during the second tier. Main effects for reach-level variables were 264 added to the model based on aforementioned criteria described for the second tier. For the last 265 tier, we added the segment-level geosoil categories to the model as main effects. Because 266 traditional residual plots are uninformative for models with binary response variables, we 
267 examined binned residual plots (Gelman and Hill 2007) to assess the fit of our final model. We 268 bootstrapped $95 \%$ confidence intervals for coefficients of main effects in the final model using 269 the "bootMer" function in $\operatorname{lme} 4(n=1,000)$ and extracted variance components for random 270 effects. Model coefficients are reported on the logit scale. We used linear combinations of 271 coefficients from our final model to calculate capture probability at varying levels of predictor

272 variables to improve relationship interpretation, where estimates were back transformed from the 273 logit scale.

We performed a leave-one-out cross validation to assess "on the ground" performance of 275 our final model at the reach scale. For each cross-validation test $(n=34)$, we removed one 276 stream reach from the dataset and modeled the remaining data using predictor variables included 277 in our final model. Thus, the cross-validation allowed us to test the predictive ability of our final 278 model at 34 "new" stream reaches (i.e., we tested the model, with less information, against data 279 it had never seen 34 times). We used values of TL and reach-scale environmental characteristics 280 and the segment-scale geosoil classification for the left-out stream reach to derive back

281 transformed species capture probabilities for each stream reach based on linear combinations of 282 model coefficients. Capture probability for each species was calculated using the median TL of $283 \quad 25-\mathrm{mm}$ size classes and the weighted average was used to represent overall species capture 284 probability. We compared model-predicted capture probabilities at the left-out stream reach to 285 observed recapture proportions for species with both $\geq 1$ recapture and $\geq 20$ marked individuals. 286 We assessed the bias and relative accuracy of our final model. Model bias was calculated as $287 \quad$ (2) $\quad \operatorname{Bias}=\frac{1}{n} \sum_{i=1}^{n}\left(\hat{y}_{i}-y_{i}\right)$,

288 where $n$ is the number of species capture probabilities examined across all cross-validation tests, $289 \hat{y}_{i}$ is the model-predicted capture probability, and $y_{i}$ is the observed recapture proportion. 
290 We used root-mean-square deviation (RMSD) to assess relative accuracy. RMSD is a more

291 conservative measure of model accuracy than mean absolute error because error in model-

292 predicted estimates are inflated as they deviate further from the observed value (Freund et al.

293 2010). RMSD was calculated as

294

(3) $\quad \mathrm{RMSD}=\sqrt{\frac{1}{n} \sum_{i=1}^{n}\left(\hat{y}_{i}-y_{i}\right)^{2}}$.

295 Although the observed recapture proportions of species at stream reaches provided an

296 informative reference to compare model estimates of capture probability, there of course was

297 inherent uncertainty with respect to representing "true "capture probability. Thus, we also

298 calculated $95 \%$ binomial probability confidence intervals for observed recapture proportions at

299 left-out stream reaches using the exact Clopper-Pearson method (Freund et al. 2010), which

300 provided a plausible range of "true" capture probabilities. We calculated a single binomial

301 probability confidence interval for each species (not size bin) both for simplicity and to construct

302 more restrictive intervals to test model predictions (i.e., confidence intervals would have been

303 wider for each size bin due to smaller sample size). We evaluated how often model-predicted

304 species capture probabilities were contained in the intervals. Because there was also uncertainty

305 in the model estimates, we also assessed how often $95 \%$ confidence intervals around model-

306 predicted capture probability overlapped with the binomial probability confidence intervals. The

307 delta method (Oehlert 1992) was used to estimate standard error for model coefficients prior to

308 back transforming to the probability scale, where we used the package msm (Jackson 2011) in

309 the statistical software R.

\section{Results}


312 Fish sampling and environmental measurements. - We marked 17,123 centrarchids across the 34

313 stream reaches (mean \pm SD: $504 \pm 302$ fish; Table 2; see also online Supplementary Material

314 Table $\mathrm{S}^{1}$ ). As expected, Micropterus size was greater and more variable than other centrarchids,

315 rock bass tended to be larger than Lepomis, and longear sunfish (Lepomis megalotis) was the

316 most abundant species. Reach-scale environmental characteristics varied considerably, with the

317 exception of instream large wood and water temperature (Table 1). In particular, discharge was

318 highly variable among stream reaches and we sampled under both low- and high-flow

319 conditions. Stream reaches were distributed among 20 stream segments and approximately half

320 the segments were classified as cherty limestone.

321 Capture probability model. - The predictor variables in our final model resulting from the

322 selection process comprised fish TL, seven reach-level environmental characteristics, and the

323 geosoil categories (Table 1 and Table 3). The reach-level main effects provided a comprehensive

324 characterization of stream sampling conditions, which included a percent riffle-discharge

325 interaction term. The final model also included random species slopes for water depth and

326 discharge (Table 3 and Table 4). Remaining variation in capture probability was lower among

327 stream segments (variance \pm SD: $0.01 \pm 0.08)$ than stream reaches $(0.04 \pm 0.21$; see online

328 Supplementary Material Fig. S $1^{1}$ ). The binned residual plot indicated adequate model fit (see

329 online Supplementary Material Fig. S2 ${ }^{1}$ ). Approximately 95\% of the binned residuals were

330 contained in theoretical error bounds and the plot did not reveal any concerning trends (Gelman

331 and Hill 2007). None of the bootstrapped 95\% confidence intervals overlapped with zero for

332 coefficients of main effects that could be interpreted in that sense (i.e., significance; Table 3).

333 The coefficient for the percent riffle main effect was interpreted with respect to the percent riffle-

334 discharge interaction term (i.e., the relationship with capture probability was dependent on 
335 different levels of both predictor variables). Because water depth was modeled among species

336 (i.e., varying slopes), it was interpreted only with respect to the species-dependent terms (Table

3374 ; i.e., the coefficient for the main effect represents the average relationship among species). The

338 coefficient for the discharge main effect was interpreted in context of both the percent riffle-

339 discharge interaction term and the species-dependent terms.

340 The relationship between predictor variables in the final model and estimated

341 electrofishing capture probability was heterogeneous both among and across centrarchids. As

342 expected, there was a strong positive relationship between capture probability and fish size

343 (Table 3). Capture probability was higher for all geosoil categories relative to shale, but there

344 was a stronger positive relationship with stony alluvium. Capture probability deceased across

345 species with increasing emergent vegetation, water clarity, and wetted channel width-depth ratio.

346 Although we adjusted electrofishing power across stream reaches, there was a moderate increase

347 in capture probability with increasing ambient water conductivity across species. There was no

348 capture probability-riffle habitat relationship under higher flow conditions (Fig. 2A). However,

349 capture probability increased with increasing riffle habitat under low-flow conditions due to the

350 discharge-percent riffle interaction (Fig. 2B). Thus, the percent riffle-discharge interaction

351 resulted in a sharp increase in estimated capture probability at low flows, even with a moderate

352 amount of riffle habitat (Fig. 2C). Although the increase in estimated capture probability under

353 low flows (i.e., the interaction term) was similar across species, the nature of the relationship

354 with stream discharge varied among species (Table 3 and Table 4). For example, there was no

355 relationship between green sunfish (Lepomis cyanellus) capture probability across higher flow

356 conditions, with an increase under low flows similar to other species (Fig. 3). The relationship

357 between capture probability and water depth also varied among stream fishes (Table 4). For 
358 example, there was no water depth-capture probability relationship for longear sunfish, but 359 capture probability decreased with deeper conditions for other species (Table 4; Fig. 4). The negative relationship with water depth was most pronounced for smallmouth bass, where capture 361 probability was much higher in shallower stream reaches compared to deeper reaches (Fig 4). The cross-validation test comparisons $(n=124)$ indicated that the final model performed

363 well with respect to predicting electrofishing capture probability among centrarchids at the reach 364 scale across a range of sampling conditions. Capture probability estimates did not tend to either overpredict or underpredict when compared to observed recapture proportions (overall bias was

366 0.00; Table 5). Capture probability estimates tended to be lower than the observed recapture 367 proportion for both redear sunfish (Lepomis microlophus) and warmouth (Lepomis gulosus).

368 However, we were only able to make a small number of comparisons due to the relatively small 369 size for these less-common centrarchids in our study area (Table 1). Overall RMSD across the 370 cross-validation tests was 0.10 (Table 5). RMSD was lowest for smallmouth bass (0.13), which 371 was not surprising due to the degree of heterogeneity in capture probability across levels of both 372 discharge and water depth (Table 4). Model-estimated capture probability compared favorably to 373 the observed recapture proportions when accounting for inherent uncertainty. Capture probability 374 estimates were contained in $95 \%$ binomial probability confidence intervals $90 \%$ of the time, with 375 similar trends among species (Table 5). Only one 95\% confidence interval around model376 estimated capture probability did not overlap with the binomial probability confidence intervals 377 (Table 5). 
380 We detailed an effective, yet straightforward, approach to model capture probability among

381 stream fishes at multiple spatial scales with practical applications for research and management.

382 We sampled across a wide range of conditions and identified multiple environmental

383 characteristics associated with heterogeneous electrofishing capture probability. A novel aspect

384 of our study was using geospatial data to generalize lithological characteristics among stream

385 reaches, which allowed us to account for coarse-scale factors associated with variation in capture

386 probability. The inclusion of the geosoil groups not only reduced field effort, but also increased

387 the spatial extent of the model's applicability. For example, stream reaches across a broad spatial

388 area may sometimes share temporally-variable instream characteristics, but differ in underlying

389 lithology that contribute to variation in stream-fish capture probability. Our study supports well-

390 informed stream-fish management and conservation decisions and promotes the establishment of

391 species-environment relationships. Although we chose to model capture probability of stream-

392 dwelling centrarchids using tow-barge electrofishing, the gear calibration approach described

393 here is easily adaptable to other fish species and sampling gears.

Our findings highlight the complexity of capture probability across the dynamic stream

395 landscape. Low flows resulted in very shallow (sometimes dry) riffles and sharp increases in 396 capture probability, particularly with higher proportions of riffle habitat. The disconnected riffle-

397 run-pool sequences not only eliminated potential fish movement across deeper riffle areas, but 398 may also have altered centrarchid habitat use. For example, Hafs et al. (2010) found that

399 smallmouth bass tended to congregate in shallow areas at low flows, presumably due to altered 400 foraging strategies. The combination of less available run and pool habitat and the occupancy of 401 shallow areas at low flows potentially explains the sharp increase in capture probability at sites 
402 with high proportions of riffle. Fish became highly susceptible to electrofishing by being 403 concentrated in shallow-water areas.

We identified species-dependent capture probability relationships among taxonomically405 and morphologically-similar stream fishes that could be related to differences in habitat use and 406 behavior. For example, the weak relationship between green sunfish capture probability and 407 discharge could be explained by their feeding strategy. Green sunfish are sit-and-wait predators, 408 which results in an affinity for structure in calmer stream areas (Werner and Hall 1977; Stuber et 409 al. 1982). Thus, green sunfish would be expected to have similar capture probability across flow 410 conditions. Conversely, capture probability would be expected to decrease with increasing 411 discharge for species occupying areas of higher flow due to the increased difficulty of netting 412 shocked fish. Smallmouth bass capture probability was likely reduced at higher flows relative to 413 other centrarchids due to their tendency to move downstream when approached by the 414 electrofishing crew, which made capture difficult at stream reaches with elevated discharge. 415 Decreasing smallmouth bass capture probability with increasing depth was also not surprising 416 given that this species is associated with deep pools in Ozark streams (Brewer 2013); however, 417 the magnitude of the relationship was an interesting finding. Our findings indicate that longear 418 sunfish capture probability did not vary with changes in depth. Longear sunfish typically occupy 419 shallow pools and runs (Laughlin and Werner 1980; Bietz 1981); therefore, increased availability 420 of deep water habitats would not be expected to influence capture probability.

421 The flexible hierarchical framework of GLMMs promoted robustness in our capture 422 probability estimates, accommodated the multilevel structure of our dataset and the unequal 423 sample sizes, and allowed us to model species simultaneously. Our capture probability estimates 424 reflected data collected across all stream reaches and species because each coefficient for a 
425 random effect shares information (i.e., borrowing strength) and is pulled towards a common

426 value (shrinkage; Pinheiro and Bates 2000). For example, treating stream reach as a random

427 effect (i.e., modeling the variance) resulted in reach-specific intercepts that represented a

428 compromise (i.e., partial pooling) between estimates obtained from separate reach-specific

429 analyses (no-pooling) and an analysis that assumed all reaches had the same intercept (complete

430 pooling). Partial pooling and shrinkage reduce bias in coefficients for main effects and increase

431 reliability in model estimates (Wagner et al. 2006; Gelman and Hill 2007). The hierarchical

432 model framework and shrinkage also increased the reliability of estimates at sites where basic

433 mark-recapture assumptions would not have been met (e.g., too few marked or recaptured fish)-,

434 which is impossible when modeling each site individually (Dorazio et al. 2005). Additionally,

435 treating species as a random effect and allowing the slopes to vary with instream characteristics

436 resulted in a single multispecies model. The multispecies GLMM was both a superior and more

437 statistically-appropriate approach than fitting separate generalized linear models (GLMs)

438 because it promoted better species-specific fit and valid comparisons could be made among

439 species (Jamil et al. 2013). Also, the ability to borrow strength from the entire ensemble of data

440 allowed us to provide capture probability estimates that had a degree of robustness for data-poor

441 species, which would have been impossible with a single-species GLM. A multispecies GLM

442 that treated species as a fixed categorical effect would have been unlikely to converge if all

443 species were included due to the additional parameters and unequal sample sizes. The inclusion

444 of additional species, even those with small sample size, was beneficial in the hierarchical

445 modeling framework because it promoted robustness in the random effect variance components.

446 Additional species can seamlessly be added to the model, where initially capture probability 
447 estimates would be strongly pulled towards the grand mean, but over time (i.e., as sample size 448 increased) also reflect species-specific fit.

450 complexity and practicality. Hierarchical capture probability models are increasingly common in 451 the fisheries literature and the statistical advantages are well described here and elsewhere (e.g., 452 Wyatt 2002; Rivot et al. 2008; Ruiz and Laplanche 2010). Nevertheless, improved statistical 453 techniques to account for variable capture probability have rarely been applied by stream-fish 454 researchers and managers (Gwinn et al. 2016). We argue that the increased complexity of 455 improved analytical methods has contributed to the minimal implementation by stream-fish 456 scientists and authors describing these techniques have tended to focus more on statistical 457 nuances than practical applications (but see Mäntyniemi and Romakkaniemi 2002; Dorazio et al. 458 2005; Gwinn et al. 2011). For example, Bayesian hierarchical approaches to model stream-fish 459 capture probability (e.g., Rivot et al. 2008; Webster et al. 2008; Price and Peterson 2010) offer 460 even more flexibility and potentially more precise estimates than the maximum likelihood 461 framework we describe here. However, the statistical complexity and challenging software (e.g., 462 WinBUGS) that comes with Bayesian approaches may not be a desirable trade-off for many 463 stream-fish scientists. The modeling framework that we present here is by no means simple. 464 However, the gear calibration approach can be easily replicated by anyone with a reasonable 465 understanding of hierarchical models and R coding (described elsewhere for these models; Jamil 466 et al. 2013; Bates et al. 2014) and could certainly be done in a Bayesian framework if desired 467 (e.g., Price and Peterson 2010). In conjunction with necessary statistical jargon, we provided 468 systematic details from the data-collection process through the selection of predictor variables. 469 We also highlighted "real-world" applications of our approach, which includes reliable reach- 
470 scale capture probability estimates and the reduction of sampling effort over time when

471 incorporated into long-term stream-fish monitoring.

Our model allowed a fish-level predictor variable (TL) to be included without the need

473 for individual recognition. Both Ford et al. (2012) and Breton et al. (2013) detail effective mark-

474 recapture methods to account for heterogeneity in capture probability among individuals;

475 however, neither model is practical if inherent individual recognition is difficult (most fish

476 species) or a very large number of fish will be marked. Although accurate measures of fish size

477 were critical for our method to be effective, this assumption would be essential to any model that 478 accounted for size variation among individuals. Price and Peterson (2010) used a method to ours 479 using size bins. We chose to model total length at the individual level before generating size bins 480 that were more practical for the reach-scale species capture probability estimates. Our method 481 could easily be extended to other fish-level characteristics that may influence capture probability 482 (e.g. sex) and is not limited by sample size. The cross-validation procedure provided a means to assess the "on the ground"

484 performance of our final model. From a practical perspective, the model performed well with 485 respect to providing reliable capture probability estimates. Capture probability estimates that 486 differed considerably from observed recapture proportions at stream reaches could sometimes be 487 explained by atypical sampling conditions. Evansville Creek, the stream reach where we 488 encountered extreme low-flow conditions $\left(0.09 \mathrm{~m}^{3} \cdot \mathrm{s}^{-1}\right)$, had the highest number of capture 489 probability estimates not contained in the binomial probability confidence intervals ( 3 of 5). The 490 model tended to overestimate capture probability at Evansville Creek; however, this was not 491 surprising due to the higher level of uncertainty at very low flow (Figure 2). Furthermore, we 492 were extrapolating when predicting capture probability at Evansville Creek because these data 
493

494

495

496

497

498

499

500

501

502

503

504

505

506

507

508

509

510

511

512

513

514

515

were removed from the cross-validation test. Therefore, our final model based on all available data would presumably perform better at another site sampled under extreme low flows. We could relate other instances where the model-estimated capture probabilities differed considerably from observed recapture proportions to unusual observations. For example, recapture proportion was curiously low for longear sunfish at Lost Creek (0.03) and uncommonly high for rock bass at Fivemile Creek (0.55). It is reasonable to assume that our model-derived estimates, which were a reflection of data collected across all sites, better represented expected capture probability under the given sampling conditions on occasions where recapture proportions were unusual.

Gear calibration is not without its limitations. A considerable amount of effort is required before sampling intensity can be reduced to a single event. Although here we report favorable results with only two intensive field seasons, remaining "noise" in the model would be expected to continue to decrease over time with additional repeat sampling. We also experienced periodic rainfall throughout both our field seasons, which increased the environment variability encountered during sampling. As we demonstrated with the cross-validation test at Evansville Creek, the model would not be expected to predict well outside of environmental conditions measured during the gear calibration process. Thus, additional repeat sampling would be required if new conditions were encountered and additional geospatial data may need to be compiled if the spatial extent of sampling increased. Similarly, additional repeat sampling would be required if fish size varied considerably from year-to-year to effectively model its relationship with capture probability or if new species were being considered. The amount of sampling necessary for effective gear calibration depends on system dynamics, the species of interest, and the level of model precision desired to meet research or management objectives. Although gear 
516 calibration leads to reduced sampling effort over time, additional effort is required for all sites to

517 compile data for predictor variables. However, we required $<2 \mathrm{~h}$ at each site to measure the

518 physicochemical parameters and the spatial data used for the geosoil categories were easily

519 obtained.

The relationships that we identified between stream-fish capture probability and

521 environmental variables may not be analogous to other systems, species, or sampling gears. For

522 example, instream large wood has been associated with stream-fish capture probability (Kruse et

523 al. 1998; Rosenberger and Dunham 2005; Price and Peterson 2010), but this variable was not

524 included in our final model. Instream large wood likely did not vary enough among our stream

525 reaches to contribute to variation in capture probability. Also, seining has been shown to have

526 different capture probability relationships with environmental variables than electrofishing (Price

527 and Peterson 2010; Pregler et al. 2015). Stream-fish researchers and managers performing gear

528 calibration might benefit from measuring a comprehensive suite of environmental variables they

529 hypothesize will influence capture probability rather than solely relying on results of other

530 studies, particularly those involving dissimilar species, different gears, or conducted in different

531 ecoregions.

532 A recent trend in freshwater fisheries is advocating standardized sampling to promote

533 comparability of datasets both within and among regions (e.g., Bonar et al. 2009; Bonar et al.

534 2015; Bonar et al. 2017). Standardizing methods (e.g., gear type, procedures, and effort) and,

535 when feasible, environmental conditions are important foundations of stream-fish research and

536 monitoring protocols. For example, standardization can minimize human-induced influences on

537 capture probability and reduce model data dimensionality. However, we demonstrated that

538 standardization does not alleviate the inferential issues associated with heterogeneous stream-fish 
539 capture probability (see also Peterson et al. 2004; Price and Peterson 2010; Mollenhauer and

540 Brewer 2017). We used standardized two-pass electrofishing at all sites, yet capture probability

541 varied considerably in relation to instream dynamics. Clearly, standardizing multiple instream

542 characteristics across space and time to minimize variability in capture probability is unrealistic.

543 We also attempted to standardize electrofishing power using accepted guidelines (Miranda

544 2009); however, capture probability still increased with increasing ambient water conductivity.

545 Electrofishing capture probability also varied among both stream reaches due to differences in

546 lithology and centrarchids. Thus, our findings highlight the challenges and limitations of using a

547 standardized stream-fish sampling approach, particularly across regions and species, for

548 comparable datasets. Relying blindly on standardization (i.e., not considering the multifaceted

549 factors that can influence capture probability) can result in gross misrepresentations of stream-

550 fish population size and assemblage structure. More importantly, inaccurate population

551 assessments can lead to inappropriate conservation and management decisions and impede

552 progress in stream-fish ecology.

The gear calibration approach we detail here requires an acceptable level of effort relative

554 to the long-term benefits and balances complexity with practicality. Approaches that focus on 555 applicability in conjunction with statistical intricacies promote increased implementation of

556 stream-fish studies and monitoring efforts that both account for variable capture probability and 557 sample across a broader range of conditions to establish species-environment relationships. We 558 believe applications similar or complementary to the approach presented here will both 559 maximize available resources and promote advances in stream-fish ecology and management. 
562 This research is a contribution of the Oklahoma Cooperative Fish and Wildlife Research Unit

563 (U.S. Geological Survey, Oklahoma Department of Wildlife Conservation, Oklahoma State

564 University, and Wildlife Management Institute cooperating). Funding was provided by the

565 Oklahoma Department of Wildlife Conservation (F13AF00192). This research was conducted

566 under the auspices of the Oklahoma State University Animal Care and Use Committee (ACUP

567 AG-14-9). We thank Trevor Mattera, Jake Holliday, Emily Gardner, Steven Maichak, Becky

568 Long, Desiree Williams, and biologists of the Oklahoma Department of Wildlife Conservation

569 for technical assistance. We thank Tyler Wagner, Andrew Taylor, and three anonymous

570 reviewers for reviewing earlier drafts. We also thank the Ozark Plateau National Wildlife Refuge

571 for providing lodging during some of our sampling. Any use of trade, firm, or product names is

572 for descriptive purposes only and does not imply endorsement by the U.S. Government.

573

$574 \quad$ References

575 Bardygula-Nonn, L.G., Nonn, R., and Savitz, J. 1995. Influence of pulsed direct current electrofishing on mortality and injuries among four centrarchid species. North Am. J. Fish. Manage. 15(4): 799-803. doi:10.1577/1548-8675(1995)015<0799:IOPDCE >2.3.CO

578 $; 2$.

579 Bates, D., Maechler, M., Bolker, B., and Walker, S. 2014. lme4: Linear mixed-effects models using Eigen and S4. J. of Stat. Software. 67(1): 1-48. doi:10.18637/jss.v067.i01.

Bietz, B.F. 1981. Habitat availability, social attraction and nest distribution patterns in longear sunfish (Lepomis megalotis peltastes). Environ. Biol. Fishes, 6(2): 193-200. doi:10.1007/BF00002782.

584 Bonar, S.A., Contreras-Balderas, S., and Iles, A.C. 2009. An introduction to standardized 
sampling. In Standard methods for sampling North American freshwater fishes. Edited by S.A. Bonar, W.A. Hubert, and D.W. Willis. American Fisheries Society, Bethesda, Maryland. pp. 1-12.

Bonar, S.A., Mercado-Silva, N., Rahr, M., Torrey, Y.T., and Cate, Jr, A. 2015. A simple webbased tool to compare freshwater fish data collected using AFS standard methods. Fisheries, 40(12): 580-589. doi:10.1080/03632415.2015.1106944.

Bonar, S.A., Mercado-Silva, N., Hubert, W.A., Beard Jr, T.D., Dave, G., Kubečka, J., Graeb, B.D., Lester, N.P., Porath, M., and Winfield, I.J. 2017. Standard methods for sampling freshwater fishes: opportunities for international collaboration. Fisheries, 42(3): 150-156. doi:10.1080/03632415.2017.1276352.

Breton, A.R., Hawkins, J.A., and Winkelman, D.L. 2013. Correcting length-frequency distributions for imperfect detection. North Am. J. Fish. Manage. 33(6): 1156-1165. doi:10.1080/02755947.2013.829141.

Brewer, S.K. 2013. Channel unit use by smallmouth bass: do land-use constraints or quantity of habitat matter? North Am. J. Fish. Manage. 33(2): 351-358. doi: 10.1080/02755947.2013.763878.

Broman, K.W., and Speed, T.P. 2002. A model selection approach for the identification of quantitative trait loci in experimental crosses. Journal of the Royal Statistical Society: Series B (Statistical Methodology), 64(4): 641-656. doi:10.1111/1467-9868.00354.

Burnham, K. P., and Anderson, D.R. 2001. Kullback-Leibler information as a basis for strong inference in ecological studies. Wildl. Res. 28(2): 111-119. doi:10.1071/WR99107.

Carle, F.L., and Strub, M.R. 1978. A new method for estimating population size from removal data. Biometrics, 34(4): 621-630. doi:10.2307/2530381. 
608 609

610

611

612

613

614

615

616

617

618

619

620

621

622

623

624

625

626

627

628

629

630

Cleary, R.E., and Greenbank, J. 1954. An analysis of techniques used in estimating fish populations in streams, with particular reference to large non-trout streams. J. Wildl. Manage. 18(4): 461-477. doi:10.2307/3797081.

Dauwalter, D.C., and Fisher, W.L. 2007. Electrofishing capture probability of smallmouth bass in streams. North Am. J. Fish. Manage. 27(1): 162-171. doi:10.1577/M06-008.1.

Dolan, C.R., Miranda, L.E., and Henry, T.B. 2002. Electrofishing for crappies: electrical settings influence immobilization efficiency, injury, and mortality. North Am. J. Fish. Manage. 22(4): 1442-1451. doi: 10.1577/1548-8675(2002)022<1442:EFCESI $>2.0 . C O ; 2$.

Dolan, C.R., and Miranda, L.E. 2004. Injury and mortality of warmwater fishes immobilized by electrofishing. North Am. J. Fish. Manage. 24(1): 118-127. doi: 10.1577/M02-115.

Dorazio, R.M., Jelks, H.L., and Jordan, F. 2005. Improving removal-based estimates of abundance by sampling a population of spatially distinct subpopulations. Biometrics 61(4): 1093-1101. doi:10.1111/j.1541-0420.2005.00360.x.

Dunham, J.B., Rosenberger, A.E., Thurow, R.F, Dolloff, C.A., and Howell, P.J. 2009. Coldwater fish in wadeable streams. In Standard methods for sampling North American freshwater fishes. Edited by S.A. Bonar, W.A. Hubert, and D.W. Willis. American Fisheries Society, Bethesda, Maryland. pp. 119-138.

Ford, J.H., Bravington, M.V., and Robbins, J. 2012. Incorporating individual variability into mark-recapture models. Methods in Ecology and Evolution, 3(6): 1047-1054. doi: 10.1111/j.2041-210X.2012.00243.x.

Freund, R.J, Wilson, W.J., and Mohr, D.L. 2010. Statistical methods. Elsevier, San Diego, California.

Gelman, A., and Hill, J. 2007. Data analysis using regression and multilevel/hierarchical models. 
631

632

633

634

635

636

637

638

639

640

641

642

643

644

645

646

647

648

649

650

651

652

653

Cambridge University Press, United Kingdom.

Gordon, N.D., McMahon, T.A., Finlayson, B.L., Gippel, C.J., and Nathan, R.J. 2004. Measurement of discharge (streamflow). In Stream hydrology: an introduction for ecologists, $2^{\text {nd }}$ ed. John Wiley \& Sons Ltd., Chichester, UK. pp. 92-101.

Gwinn, D.C., Beesley, L.S., Close, P., Gawne, B., and Davies, P.M. 2016. Imperfect detection and the determination of environmental flows for fish: challenges, implications and solutions. Freshwater Biol. 61(1): 172-180. doi:10.1111/fwb.12684.

Gwinn, D.C., Brown, P., Tetzlaff, J.C, and Allen, M.S. 2011. Evaluating mark-recapture sampling designs for fish in an open riverine system. Mar. Freshwater Res. 62(7): 835840. doi:10.1071/MF10217.

Hafs, A.W., Gagen, C.J., and Whalen, J.K. 2010. Smallmouth bass summer habitat use, movement, and survival in response to low flow in the Illinois Bayou, Arkansas. North Am. J. Fish. Manage. 30(2): 604-612. doi:10.1577/M08-183.1.

Huggins, R.M. 1991. Some practical aspects of a conditional likelihood approach to capture experiments. Biometrics 47(2): 725-732. doi:10.2307/2532158.

Jackson, C.H. 2011. Multi-state models for panel data: the msm package for R. J. of Stat. Software 38(8): 1-29. doi:10.18637/jss.v038.i08.

Jackson, D.A., Peres-Neto, P.R., and Olden, J.D. 2001. What controls who is where in freshwater fish communities - the roles of biotic, abiotic, and spatial factors. Can. J. Fish. Aquat. Sci. 58(1): 157-170. doi:10.1139/f00-239.

Jamil, T., Opdekamp, W., van Diggelen, R., and ter Braak, C.J.F. 2012. Trait-environment relationships and tiered forward model selection in linear mixed models. Int. J. Ecol. doi:10.1155/2012/947103. 
654 655

656

657

658

659

660

661

662

663

664

665

666

667

668

669

670

671

672

673

674

675

676

Jamil, T., Ozinga, W.A., Kleyer, M., and ter Braak, C.J.F. 2013. Selecting traits that explain species-environment relationships: a generalized linear mixed model approach. J. Veg. Sci. 24(6): 988-1000. doi:10.1111/j.1654-1103.2012.12036.x.

Kruse, C.G, Hubert, W.A., and Rahel, F.J. 1998. Single-pass electrofishing predicts trout abundance in mountain streams with sparse habitat. North Am. J. Fish. Manage.18(4): 118-127. doi:10.1577/1548-8675(1998)018<0940:SPEPTA $>2.0 . C O ; 2$.

Larimore, R.W. 1961. Fish population and electrofishing success in a warm-water stream. J. Wildl. Manage. 25(1): 1-12. doi:10.2307/3796984.

Laughlin, D.R., and Werner, E.E. 1980. Resource partitioning in two coexisting sunfish: pumpkinseed (Lepomis gibbosus) and northern longear sunfish (Lepomis megalotis peltastes). Can. J. Fish. Aquat. Sci. 37(9): 1411-1420. doi:10.1139/f93-209.

Lyons, J., and Kanehl, P. 1993. A comparison of four electroshocking procedures for assessing the abundance of smallmouth bass in Wisconsin streams. U. S. Dept. Agri. Gen. Tech. Rep. NC-159. Available from http://www.nrs.fs.fed.us/pubs/gtr/gtr_nc159.pdf [accessed 17 July 2016].

MacKenzie, D.I., Nichols, J.D., Royle, J.A., Pollock, K.H., Bailey, L.L., and Hines, J.E. 2005. Occupancy estimation and modeling: inferring patterns and dynamics of species occurrence. Elsevier, San Diego, California.

Manly, B.F., and Seber, G.A.F. 1973. Animal life tables from capture-recapture data. Biometrics, 29(3): 487-500. doi:10.2307/2529172.

Mäntyniemi, S., and Romakkaniemi, A. 2002. Bayesian mark-recapture estimation with an application to a salmonid smolt population. Can. J. Fish. Aquat. Sci. 59(11): 1748-1758. doi:10.1139/f02-146. 
677 McClendon, D., and Rabeni, C.F. 1986. Sampling stream centrarchids: comparing electrofishing 678 and underwater observation. Proceedings of the Annual Conference of Southeastern Association of Fisheries and Wildlife Agencies, 40(1986): 92-101.

680 681 682 683 684 685 686 687 688 689 690 691 692 693 694 695 696 697 698 699

Miller, D.A, and White, R.A. 1998. A conterminous United States multi-layer soil characteristics data set for regional climate and hydrology modeling. Earth Interact. 2(1): 2-2. doi:10.1175/1087-3562(1998)002<0001:ACUSMS >2.3.CO;2.

Miranda, L.E. 2009. Standardizing electrofishing power for boat electrofishing. In Standard methods for sampling North American freshwater fishes. Edited by S.A. Bonar, W.A. Hubert, and D.W. Willis. American Fisheries Society, Bethesda, Maryland. pp. 223-230.

Mollenhauer, R., and Brewer, S.K. 2017. Multinomial $N$-mixture models improve the applicability of electrofishing for developing population estimates of stream-dwelling smallmouth bass. North Am. J. Fish. Manage. 37(1): 211-224. doi: $10.1080 / 02755947.2016 .1254127$.

Neumann, R.M., Guy, C.S., and Willis, D.W. 2013. Length, weight, and associated indices. In Fisheries techniques, $3^{\text {rd }}$ ed. Edited by A.V Zale, D.L. Parrish, and T.M. Sutton. American Fisheries Society, Bethesda, Maryland. pp. 43-58.

Nigh, T.A., and Schroeder, W.A. 2002. Atlas of Missouri ecoregions. Missouri Depart. Cons. Comm., Jefferson City. Available from http://www.nrc.gov/docs/ML0923/ML092360302.pdf [accessed 8 August 2016].

Oehlert, G.W. 1992. A note on the delta method. Am. Stat. 46(1): 27-29. doi:10.1080/00031305.1992.10475842.

Pennsylvania State University. 2008. Soil information for enviormental modeling and ecosystem management. Available from http://www.soilinfo.psu.edu/ [accessed 8 June 2016]. 
Peterson, J.T., and Paukert, C.P. 2009. Converting nonstandard fish sampling data to standardized data. In Standard methods for sampling North American freshwater fishes. Edited by S.A. Bonar, W.A. Hubert, and D.W. Willis. American Fisheries Society, Bethesda, Maryland. pp. 195-215.

Peterson, J.T., and Rabeni, C.F. 2001. Evaluating the efficiency of a one-square-meter quadrat sampler for riffle-dwelling fish. North Am. J. Fish. Manage. 21(1): 76-85. doi: 0.1577/1548-8675(2001)021<0076:ETEOAO>2.0.CO;2.

Peterson, J.T., Thurow, R.F., and Guzevich, J.W. 2004. An evaluation of multipass electrofishing for estimating the abundance of stream-dwelling salmonids. Trans. Am. Fish. Soc. 133(2): 462-475. doi:10.1577/03-044.

Peterson, N.P., and Cederholm, C.J. 1984. A comparison of the removal and mark-recapture methods of population estimation for juvenile Coho salmon in a small stream. North Am. J. Fish. Manage. 4(1): 99-102. doi:10.1577/1548-8659(1984)4<99:ACOTRA>2.0.CO;2.

Pinheiro, J.C., and Bates, D.M. 2000. Fitting linear mixed-effects models. In Mixed-effects models in S and SPLUS. Springer, New York. pp. 133-199.

Poff, N.L., and Zimmerman, J.K.H. 2010. Ecological responses to altered flow regimes: a literature review to inform the science and management of environmental flows. Freshwater Biol. 55(1): 194-205. doi:10.1111/j.1365-2427.2009.02272.x.

Pollock, K.H. 2002. The use of auxiliary variables in capture-recapture modelling: an overview. J. Appl. Stats. 29(1-4): 85-102. doi:10.1080/02664760120108430.

Pregler, K.C., Vokoun, J.C., Jensen, T., and Hagstrom, N. 2015. Using multimethod occupancy estimation models to quantify gear differences in detection probabilities: is backpack electrofishing missing occurrences for a species of concern? Trans. Am. Fish. Soc. 
144(1): 89-95. doi:10.1080/00028487.2014.968291.

Price, A.L., and Peterson, J.T. 2010. Estimation and modeling of electrofishing capture efficiency for fishes in wadeable warmwater streams. North Am. J. Fish. Manage. 30(2): 481-498. doi:10.1577/M09-122.1.

Probst, W.E., Rabeni, C.F., Covington, W.G., and Marteney, R.E. 1984. Resource use by streamdwelling rock bass and smallmouth bass. Trans. Am. Fish. Soc. 113(3): 283-294. doi:10.1577/1548-8659(1984)113<283:RUBSRB>2.0.CO;2.

R Development Core Team. 2016. R: a language and environment for statistical computing. R Foundation for Statistical Computing, Vienna. Available from http://www.R-project.org/. [accessed 20 March 2017]

Rabeni, C.F., Lyons, L., Mercado-Silva, N., and Peterson, J.T. 2009. Warmwater fish in wadeable streams. In Standard methods for sampling North American freshwater fishes. Edited by S.A. Bonar, W.A. Hubert, and D.W. Willis. American Fisheries Society, Bethesda, Maryland. pp. 43-58.

Rivot, E., Prevost, E., Cuzol, A., Bagliniere, J-L., and Parent, E. 2008. Hierarchical Bayesian modelling with habitat and time covariates for estimating riverine fish population size by successive removal method. Can. J. Fish. Aquat. Sci. 65(1): 117-133. doi:10.1139/f07153.

Rosenberger, A.E., and Dunham, J.B. 2005. Validation of abundance estimates from markrecapture and removal techniques for rainbow trout captured by electrofishing in small streams. North Am. J. Fish. Manage. 25(4): 118-127. doi:10.1577/M04-081.1.

Royle, J.A., and Dorazio, R.M. 2006. Hierarchical models of animal abundance and occurrence. J. of Agric. Biol. Environ. Stats. 11(3): 249-263. doi:10.1198/108571106X129153. 
746 Royle, J.A., Chandler, R.B., Sollmann, R., and Gardner, B. 2013. Spatial capture-recapture.

747

748 749

750

751

752

753

754

755

756

757

758

759

760

761

762

763

764

765

766

767

768

Academic Press, Waltham, Massachusetts.

Ruiz, P., and Laplanche, C. 2010. A hierarchical model to estimate the abundance and biomass of salmonids by using removal sampling and biometric data from multiple locations. Can. J. Fish. Aquat. Sci. 67(12): 2032-2044. doi:10.1139/F10-123.

United States Geological Survey (USGS). 2005. Geospatial data gateway. Available from https://gdg.sc.egov.usda.gov/ [accessed 8 June 2016].

Schlosser, I.J. 1987. The role of predation in age- and size-related habitat use by stream fishes. Ecology 68(3): 651-659. doi:10.2307/1938470.

Stuber, R.J., Gebhart, G., and Maughan, O.E. 1982. Habitat suitability index models: green sunfish. U.S. Fish and Wildlife Service FWS/OBS: 82/10.15. Available from https://pubs.er.usgs.gov/publication/fwsobs82_10_15 [accessed 12 August 2016].

Thompson, S.K., and Seber, G.A.F. 1994. Detectability in conventional and adaptive sampling. Biometrics, 50(3): 712-724. doi:10.2307/2532785.

Williams, B.K., Nichols, J.D., and Conroy, M.J. 2002. Analysis and management of animal populations. Academic Press, San Diego, California.

Wagner, T., Hayes, D.B., and Bremigan, M.T. 2006. Accounting for multilevel data structures in fisheries data using mixed models. Fisheries, 31(4): 180-187. doi:10.1577/15488446(2006)31[180:AFMDSI]2.0.CO;2.

Webster, R. A., Pollock, K.H., Ghosh, K., and Hankin, D.G. 2008. Bayesian spatial modeling of data from unit-count surveys of fish in streams. Trans. Am. Fish. Soc. 137(2): 438-453. doi:137:438-453. 10.1577/T06-138.1.

Werner, E. E., and Hall, D. J. 1977. Competition and habitat shift in two sunfishes 
769

770

771

772

773

774

775

776

777

778

779

780

781

9

0

(Centrarchidae). Ecology, 58(4): 869-876. doi:10.2307/1936222.

Woods, A.J., Omernik, J.M, Butler, D.R., Ford, J.G, Henley, J.E., Hoagland, B.W., Arndt, D.S, and Morgan, B.C. 2005. Ecoregions of Oklahoma. Reston, Virginia, U.S. Geological Survey, map scale 1:1,000,000. Available from https://archive.epa.gov/wed/ecoregions/web/html/ok_eco.html [accessed 8 August].

Wyatt, R.J. 2002. Estimating riverine fish population size from single-and multiple-pass removal sampling using a hierarchical model. Can. J. Fish. Aquat. Sci. 59(4): 695-706. doi: 10.1139/f02-041.

Zippin, C. 1958. The removal method of population estimation. J. Wildl. Manage. 22(1): 82-90. doi:10.2307/3797301. 
Table 1. Reach-scale characteristics for 34 stream reaches in the Ozark Highlands ecoregion of northeast Oklahoma and southwest

783 Missouri during summer 2014-2015.

\begin{tabular}{|c|c|c|c|}
\hline Variable & Definition & Mean $\pm \mathrm{SD}$ & Range \\
\hline Cross-sectional area $\left(\mathrm{m}^{2}\right)$ & Mean wetted width times thalweg depth measured at $50 \mathrm{~m}$ transects & $13.5 \pm 6.5$ & $4.9-39.4$ \\
\hline$*$ Discharge $\left(\mathrm{m}^{3} \cdot \mathrm{s}^{-1}\right)$ & Mean of three replicates in a homogenous area of a run & $1.9 \pm 2.1$ & $0.09-8.52$ \\
\hline Percent cover & Percent emergent vegetation plus percent instream large wood & $5.8 \pm 5.9$ & $1-28$ \\
\hline *Percent emergent vegetation & Total area divided by sampling area times 100 & $2.8 \pm 5.6$ & $1-25$ \\
\hline Percent instream large wood & Total area divided by sampling area times 100 & $3.0 \pm 2.3$ & $1-10$ \\
\hline *Percent riffle & Total length divided by reach length times 100 & $22.0 \pm 8.8$ & $0.07-0.42$ \\
\hline Pool depth (m) & Mean maximum pool depth & $1.4 \pm 0.3$ & $1.1-4.0$ \\
\hline *Water clarity $(\mathrm{m})$ & Horizontal distance underwater observer could see a fish silhouette & $3.3 \pm 1.5$ & $1.0-7.0$ \\
\hline *Water conductivity $(\mu \mathrm{S} / \mathrm{cm})$ & Ambient conductivity measured at the downstream end of reach & $284.2 \pm 80.4$ & $160-500$ \\
\hline *Water depth (m) & Mean thalweg depth measured at $50 \mathrm{~m}$ transects & $0.8 \pm 0.2$ & $0.5-1.3$ \\
\hline Water temperature $\left({ }^{\circ} \mathrm{C}\right)$ & Measured at downstream end of the reach & $21.6 \pm 2.6$ & $16.1-25.7$ \\
\hline Wetted channel width (m) & Mean wetted width measured at $50 \mathrm{~m}$ transects & $15.1 \pm 4.7$ & $9-32$ \\
\hline *Width-depth ratio & Mean wetted width of reach divided by mean thalweg depth of reach & $18.7 \pm 5.1$ & $9.9-33.9$ \\
\hline
\end{tabular}


785 Note: * indicates reach-scale variables included in the capture probability model using the model-selection process described in the 786 text. 
787 Table 2. Summary of fish species marked in 34 stream reaches in the Ozark Highlands ecoregion 788 of northeast Oklahoma and southwest Missouri during summer 2014-2015.

\begin{tabular}{llccc}
\hline & & Number & Mean TL \pm & \\
Common name & Scientific name & marked & SD (mm) & TL range (mm) \\
& & & & \\
\hline Bluegill & Lepomis macrochirus & 1,904 & $94 \pm 25$ & $50-215$ \\
Green sunfish & Lepomis cyanellus & 2,503 & $106 \pm 29$ & $50-207$ \\
Largemouth bass & Micropterus salmoides & 513 & $175 \pm 73$ & $50-196$ \\
Longear sunfish & Lepomis megalotis & 8,595 & $94 \pm 21$ & $50-186$ \\
Redear sunfish & Lepomis microlophus & 158 & $85 \pm 24$ & $50-286$ \\
Rock bass & Ambloplites rupestris & 2,032 & $128 \pm 37$ & $52-182$ \\
Smallmouth bass & Micropterus dolomieu & 1,150 & $200 \pm 61$ & $80-460$ \\
Spotted bass & Micropterus punctulatus & 28 & $165 \pm 67$ & $80-404$ \\
Warmouth & Lepomis gulosus & 240 & $113 \pm 23$ & $90-360$ \\
\hline
\end{tabular}


791 Table 3. Coefficients and bootstrapped 95\% confidence intervals (CI) for main effects from a 792 generalized linear mixed model developed to examine heterogeneity in electrofishing capture 793 probability among stream fishes of the Ozark Highlands ecoregion.

794

\begin{tabular}{lcc}
\hline Parameter & Coefficent \pm SE & \multicolumn{1}{l}{$95 \%$ CI } \\
\hline Intercept & $-1.71 \pm 0.19$ & $(-2.09,-1.35)$ \\
TL & $0.31 \pm 0.02$ & $(0.25,0.36)$ \\
*Discharge & $-0.25 \pm 0.09$ & $(-0.42,-0.07)$ \\
Percent emergent vegetation & $-0.24 \pm 0.06$ & $(-0.37,-0.12)$ \\
Percent riffle & $0.08 \pm 0.06$ & $(-0.04,0.20)$ \\
Water conductivity & $0.18 \pm 0.07$ & $(0.05,0.31)$ \\
Water clarity & $-0.19 \pm 0.06$ & $(-0.31,-0.09)$ \\
*Water depth & $-0.10 \pm 0.09$ & $(-0.27,0.06)$ \\
Width-depth ratio & $-0.13 \pm 0.06$ & $(-0.25,-0.01)$ \\
Discharge x percent riffle & $-0.16 \pm 0.05$ & $(-0.26,-0.05)$ \\
Geosoil (Cherty alluvium) & $0.54 \pm 0.19$ & $(0.16,0.95)$ \\
Geosoil (Stony alluvium) & $1.22 \pm 0.24$ & $(0.75,1.71)$ \\
Geosoil (Cherty limestone) & $0.38 \pm 0.19$ & $(0.03,0.76)$
\end{tabular}

Note: Coefficients are reported on a logit scale. All continuous variables were standardized such

797 that each had a mean of zero and a standard deviation of one, where the model intercept 798 estimates capture probability at mean conditions and coefficients for continuous variables 799 represent a unit change of one standard deviation. Geosoil was defined as a categorical variable 
800 with shale as the reference category. Asterisks indicate site-level variables that were also 801 modeled as species-dependent random terms (Table 4).

802 
803 Table 4. Species-dependent coefficients (i.e., random intercepts and slopes) with SD from a 804 generalized linear mixed model developed to examine heterogeneity in electrofishing capture 805 probability among stream fishes of the Ozark Highlands ecoregion.

\begin{tabular}{llll} 
Species & Intercept \pm SD & Discharge \pm SD & Water depth \pm SD \\
\hline Bluegill & $-1.53 \pm 0.06$ & $-0.25 \pm 0.07$ & $-0.06 \pm 0.06$ \\
Green sunfish & $-1.48 \pm 0.06$ & $-0.07 \pm 0.06$ & $-0.10 \pm 0.05$ \\
Largemouth bass & $-1.91 \pm 0.10$ & $-0.32 \pm 0.09$ & $-0.13 \pm 0.08$ \\
Longear sunfish & $-1.61 \pm 0.05$ & $-0.30 \pm 0.04$ & $0.02 \pm 0.04$ \\
Redear sunfish & $-1.54 \pm 0.15$ & $-0.31 \pm 0.11$ & $0.01 \pm 0.11$ \\
Rock bass & $-1.91 \pm 0.07$ & $-0.14 \pm 0.07$ & $-0.15 \pm 0.06$ \\
Smallmouth bass & $-2.20 \pm 0.08$ & $-0.32 \pm 0.07$ & $-0.42 \pm 0.06$ \\
Spotted bass & $-1.80 \pm 0.21$ & $-0.28 \pm 0.11$ & $-0.12 \pm 0.13$ \\
Warmouth & $-1.37 \pm 0.12$ & $-0.25 \pm 0.10$ & $0.06 \pm 0.09$ \\
\hline
\end{tabular}

807 Note: Standard deviation was calculated as the square root of the variance for each random term. 
816 Table 5. Results of a leave-one-out cross validation that evaluated the performance of a

817 generalized linear mixed model for estimating tow-barge electrofishing capture probability

818 among fishes in 34 stream reaches of the Ozark Highlands: bias and relative accuracy (RMSD),

819 the number of estimates contained in the $95 \%$ binomial probability CI (contained), and the

820 number of times predicted 95\% CI overlapped with the binomial probability 95\% CI (overlap).

\begin{tabular}{lcccc}
\hline Species & Bias & RMSD & Contained 95\% CI & Overlapped 95\% CI \\
\hline All & 0.00 & 0.10 & $90 \%(112$ of 124$)$ & $99 \%(123 \text { of } 124)^{822}$ \\
Bluegill & -0.01 & 0.10 & $95 \%(18$ of 19$)$ & $100 \%(19 \text { of } 19)^{823}$ \\
Green sunfish & 0.01 & 0.09 & $91 \%(20$ of 22$)$ & $100 \%(22$ of 22$)$ \\
Largemouth bass & 0.00 & 0.07 & $100 \%(10$ of 10$)$ & $100 \%(10 \text { of } 10)^{825}$ \\
Longear sunfish & 0.02 & 0.08 & $87 \%(26$ of 30$)$ & $97 \%(29$ of 30$)$ \\
Redear sunfish & -0.04 & 0.07 & $100 \%(2$ of 2$)$ & $100 \%(2 \text { of } 2)^{827}$ \\
Rock bass & 0.01 & 0.11 & $90 \%(18$ of 20$)$ & $100 \%(20 \text { of } 20)^{828}$ \\
Smallmouth bass & 0.00 & 0.13 & $88 \%(15$ of 17$)$ & $100 \%(17$ of 17$)$ \\
Warmouth & -0.05 & 0.11 & $75 \%(3$ of 4$)$ & $100 \%(4$ of 4$)$ \\
\hline
\end{tabular}

832 Note: RMSD is root-mean-square error and CI is confidence interval (see Methods for a full 833 description of calculations).

834

835

836

837

838 
839 Fig 1. Thirty-four stream reaches of the Ozark Highland ecoregion in northeast Oklahoma and 840 southwest Missouri (black dots). Reaches (0.6-1 km) were sampled during summer 2014-2015 to 841 develop a capture probability model for tow-barge electrofishing.

843 Fig. 2. Electrofishing capture probability across levels of discharge and percent riffle habitat 844 using estimates from a generalized linear mixed model that included an interaction term between 845 the two predictor variables (Table 3). Panel A shows the relationship between capture probability 846 and riffle habitat at higher flows (discharge held at 1 SD). Panel B shows the relationship 847 between capture probability and riffle habitat at low flows (discharge held at $-1.5 \mathrm{SD}$ ). Panel C 848 shows the relationship between capture probability and discharge with percent riffle held at 1 849 SD, where capture probability increases sharply at lower flow due to the interaction. The $\mathrm{x}$-axes 850 represent levels of either percent riffle or discharge from -2 to 2 SD. Capture probability was 851 calculated for the average-sized longear sunfish (Lepomis megalotis), although the general 852 relationships were similar among species and across fish size (see also Fig. 3). In all of the 853 panels, other reach-level predictor variables included in the model were held at mean values and 854 the geosoil category was cherty limestone (see Table 3). Dashed lines are 95\% confidence 855 intervals.

857 Fig. 3. Relationship between electrofishing capture probability and discharge among stream 858 fishes of the Ozark Highlands using species-dependent random terms derived from a generalized 859 linear mixed model (Table 4). The left panel represents the average-size bluegill (Lepomis 860 macrochirus) and the right panel represents the average-size green sunfish (Lepomis cyanellus). 861 The $\mathrm{x}$-axis represents levels of discharge from -2 to 2 SD. Other reach-level variables included in 
862 the model were held at mean values and the geosoil category was cherty limestone (see Table 3).

863 Dashed line are 95\% confidence intervals.

864

865 Fig. 4. Relationship between electrofishing capture probability and water depth among stream

866 fishes of the Ozark Highlands using species-dependent random terms derived from a generalized

867 linear mixed model (Table 4). The left panel represents average-size smallmouth bass

868 (Micropterus dolomieu) and right panel represents the average-size longear sunfish (Lepomis

869 megalotis). The $\mathrm{x}$-axis represents levels of mean water depth from -2 to 2 SD. Other reach-level

870 variables included in the model were held at mean values and the geosoil category was cherty

871 limestone (see Table 3). Dashed line are 95\% confidence intervals.

872 


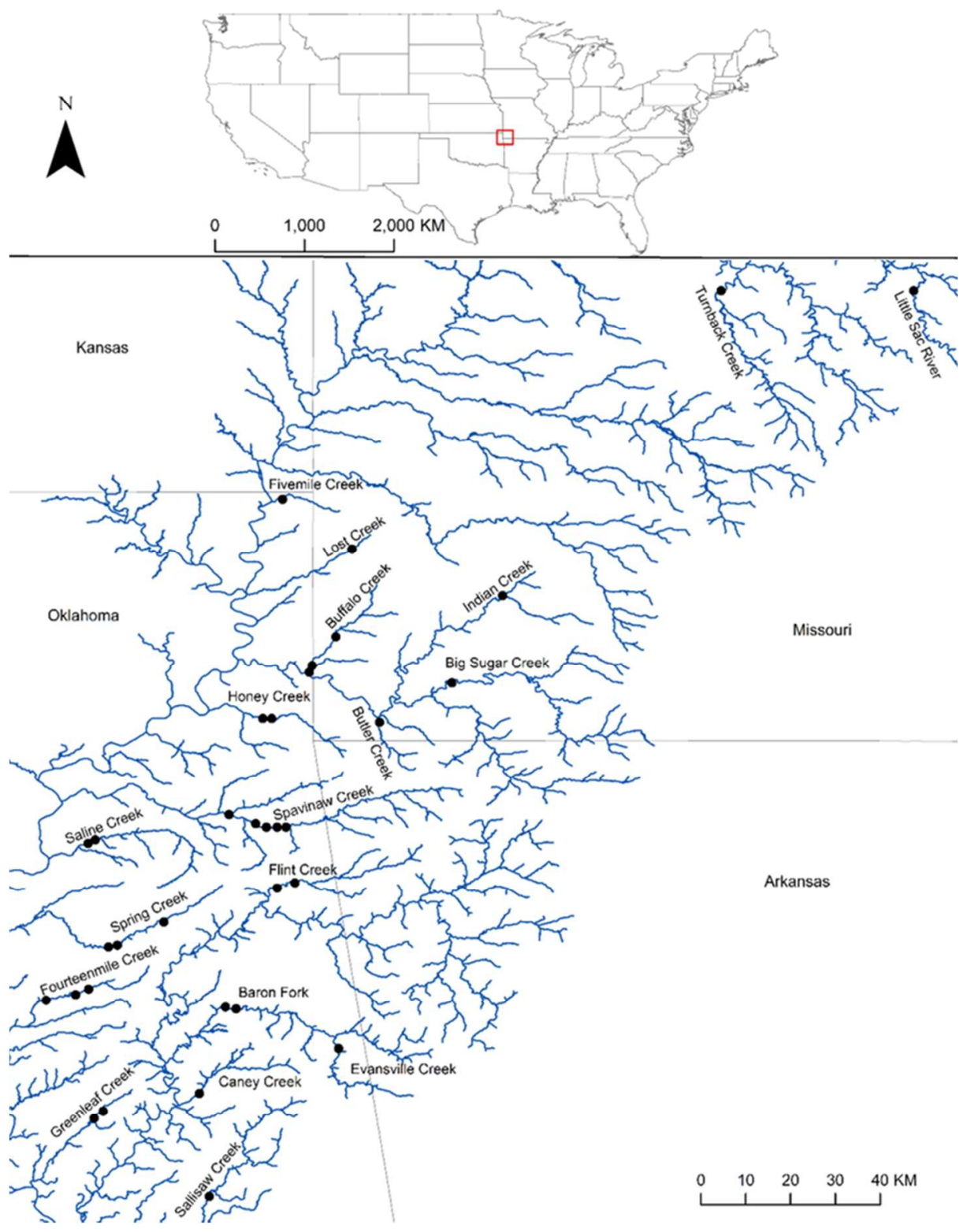

Fig 1. Thirty-four stream reaches of the Ozark Highland ecoregion in northeast Oklahoma and southwest Missouri (black dots). Reaches (0.6-1 km) were sampled during summer 2014-2015 to develop a capture probability model for tow-barge electrofishing.

$144 \times 187 \mathrm{~mm}(150 \times 150 \mathrm{DPI})$ 

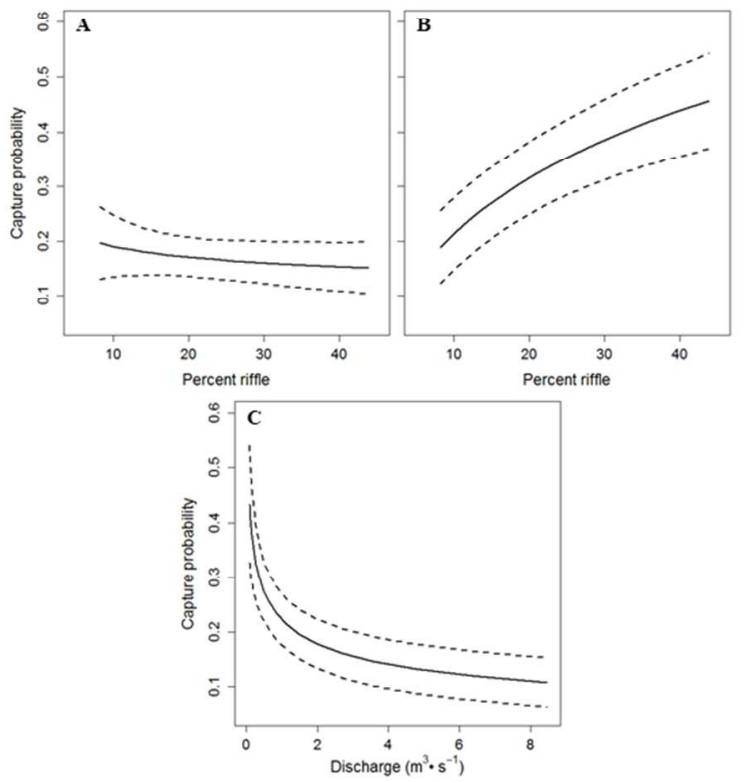

Fig. 2. Electrofishing capture probability across levels of discharge and percent riffle habitat using estimates from a generalized linear mixed model that included an interaction term between the two predictor variables (Table 3). Panel A shows the relationship between capture probability and riffle habitat at higher flows (discharge held at 1 SD). Panel B shows the relationship between capture probability and riffle habitat at low flows (discharge held at $-1.5 \mathrm{SD}$ ). Panel $\mathrm{C}$ shows the relationship between capture probability and discharge with percent riffle held at 1 SD, where capture probability increases sharply at lower flow due to the interaction. The $x$-axes represent levels of either percent riffle or discharge from -2 to 2 SD. Capture probability was calculated for the average-sized longear sunfish (Lepomis megalotis), although the general relationships were similar among species and across fish size (see also Fig. 3). In all of the panels, other reach-level predictor variables included in the model were held at mean values and the geosoil category was cherty limestone (see Table 3). Dashed lines are 95\% confidence intervals.

$254 \times 190 \mathrm{~mm}(96 \times 96 \mathrm{DPI})$ 


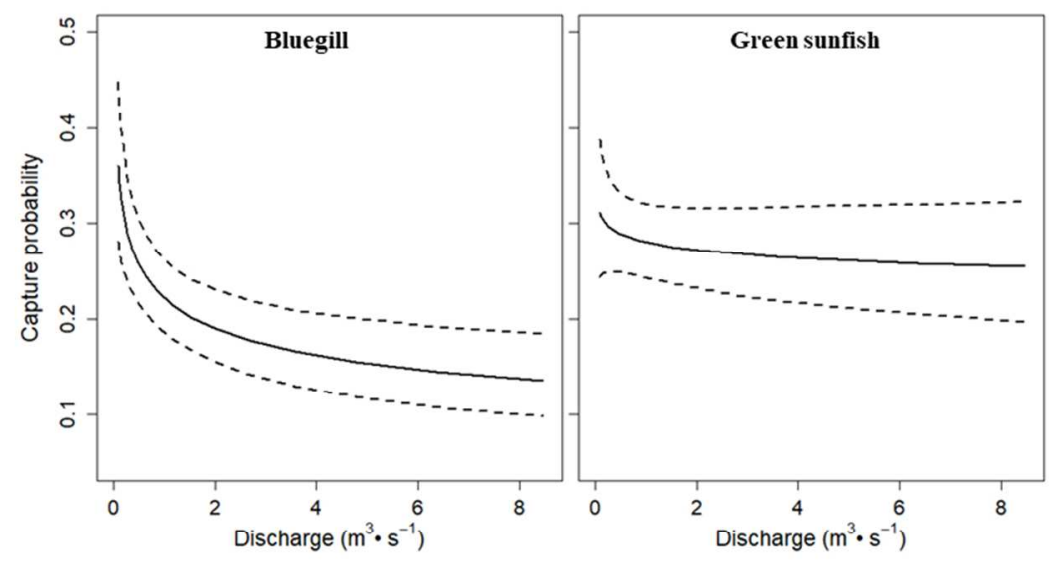

Fig. 3. Relationship between electrofishing capture probability and discharge among stream fishes of the Ozark Highlands using species-dependent random terms derived from a generalized linear mixed model (Table 4). The left panel represents the average-size bluegill (Lepomis macrochirus) and the right panel represents the average-size green sunfish (Lepomis cyanellus). The $x$-axis represents levels of discharge from -2 to 2 SD. Other reach-level variables included in the model were held at mean values and the geosoil category was cherty limestone (see Table 3). Dashed line are 95\% confidence intervals.

$254 \times 190 \mathrm{~mm}(96 \times 96 \mathrm{DPI})$ 


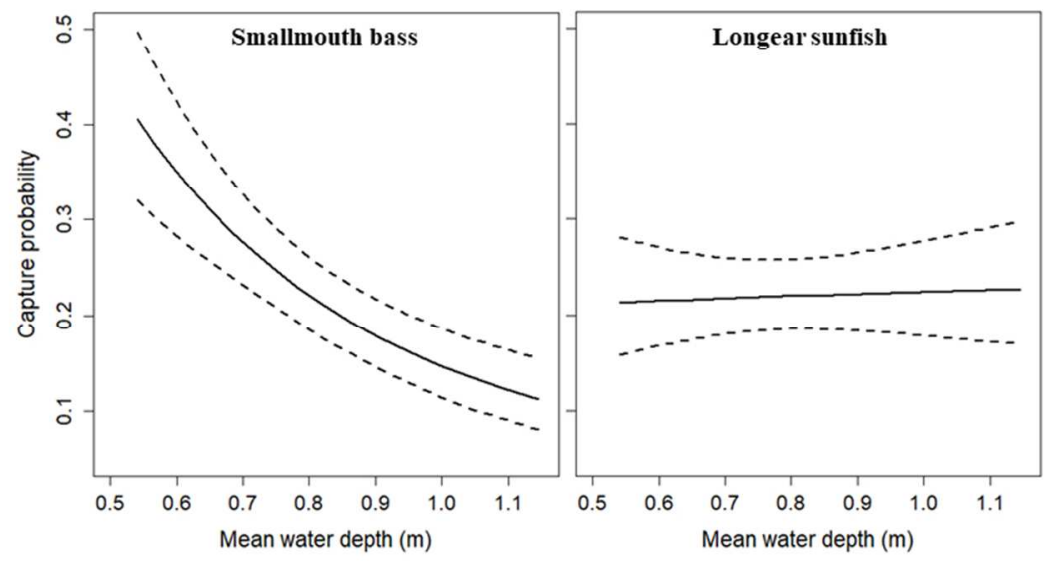

Fig. 4. Relationship between electrofishing capture probability and water depth among stream fishes of the Ozark Highlands using species-dependent random terms derived from a generalized linear mixed model (Table 4). The left panel represents average-size smallmouth bass (Micropterus dolomieu) and right panel represents the average-size longear sunfish (Lepomis megalotis). The $x$-axis represents levels of mean water depth from -2 to 2 SD. Other reach-level variables included in the model were held at mean values and the geosoil category was cherty limestone (see Table 3). Dashed line are 95\% confidence intervals.

$254 \times 190 \mathrm{~mm}(96 \times 96 \mathrm{DPI})$ 